\title{
SYNTHESIS OF PMMA BY HIGH FREQUENCY ULTRASOUND
}

\author{
C. Parra ${ }^{1}$, G. González ${ }^{1}$, C. Albano ${ }^{2}$ \\ ${ }^{1}$ Laboratorio de Ciencias e Ing. de Materiales, Dpto. de Ingeniería; e-mail: gemagonz@ivic.ve \\ ${ }^{2}$ Laboratorio de Polímeros, Centro de Química. IVIC. Altos de Pipe, Km 11; Carretera \\ Panamericana, Caracas, Venezuela.
}

Poly Methyl Methacrylate (PMMA) is a very versatile polymer due to its excellent properties such as resistance to strong alkaline or acid solutions and its stability to heat and light. PMMA can be obtained by conventional methods of polymerization in emulsion resulting in particles in the range of 1 to $20 \mu \mathrm{m}$. Recently, other methods has been used for the synthesis of this polymer, among them sonochemistry using ultrasound waves as the source of energy.

The work of Suslick and Price [1] has been pioneer in the first attends of ultrasound applications to the synthesis of materials. For instance, the sonochemistry decomposition of organometallic precursors in low volatile solvents produces nanostructure materials with high catalytic activities.

The surfactant type and concentration can affect the polymer morphology and stereoregularity. The objective of the present work was to study the influence of surfactant nature, concentration and monomer concentration in the synthesis of PMMA using high frequency ultrasonic energy. Polymerization was carried out via free radicals from an aqueous solution of different concentrations of a non-ionic Nonyl phenol etoxylade (NFE) or a cationic surfactant cetyltrimethylammonium bromide (CTAB) and different concentrations of the insoluble monomer Methyl Methacrylate (MMA) as the disperse phase. The reaction was carried out at a frequency of $20 \mathrm{kHz}$ for $1 \mathrm{~h}$ under $\mathrm{N}_{2}$ atmosphere. The concentrations of surfactants and MMA are given in table 1. The polymer particles obtained were characterized by Fourier Transformed Infrared Spectroscopy (FTIR), Differential Scanning Calorimetry (DSC) and Scanning Electron Microscopy (SEM).

The morphology of the synthesized polymer was observed in a scanning electron microscope (SEM) Hitachi Field Emission S-4500 operating at $8 \mathrm{kV}$. The samples were prepared by suspension in an ethanol-water mixture (75/25) and Pt-C coated in a Balzers BAE 300 evaporator.

The FTIR spectra showed the presence of the characteristic absorption bands for PMMA when NFE was used. When CTAB was employed, for all surfactant concentrations and high monomer concentration $(14 \% \mathrm{v} / \mathrm{v})$, PMMA was obtained. However bands of the surfactant were present for lower monomer concentrations. The glass transition temperature obtained from the DSC experiments was observed in the range of $106-126^{\circ} \mathrm{C}$ characteristic of PMMA.

Figures 1 and 2 show the SEM images of PMMA synthesized with CTAB. Agglomerated spherical particles with particle size in the range of 0,1 and $1,3 \mu \mathrm{m}$ are observed for low and high $\mathrm{CTAB}$ concentrations $(0,5$ y $2,0 \% \mathrm{p} / \mathrm{v})$. The synthesis carried out with NFE shows very well defined spherical particles with particle size in the range of 0,2 to $2,5 \mu \mathrm{m}$ (Fig. 3 and 4 ). 


\section{References}

[1] Suslick, Kenneth., Sci. 247: 1439-1445 (1990)

\begin{tabular}{|c|c|c|c|c|}
\hline Surfactant & Surfac (\%P/V) & Volume $(\mathbf{m L})$ & MMA (\%V/V) & Volume (mL) \\
\hline CTAB & 0,$5 ; 1,0 ; 1,5$ y 2,0 & 5 & 10 & 45 \\
\hline NFE & 0,$5 ; 1,0 ; 1,5 ;$ y 2,0 & 5 & 10 & 45 \\
\hline
\end{tabular}

Table No.1: Concentration of surfactant and MMA used for PMMA synthesis

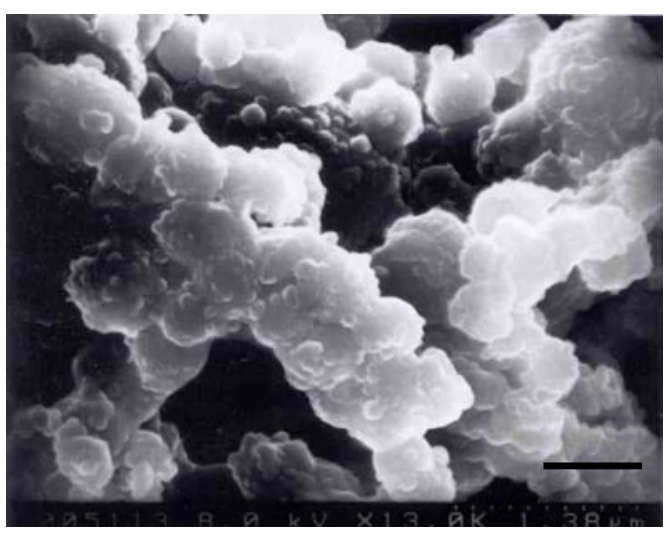

Fig. 1 PMMA synthesized with $0.5 \% \mathrm{p} / \mathrm{v}$ CTAB and $10 \% \mathrm{v} / \mathrm{v}$ MMA

Bar: $0.4 \mu \mathrm{m}$

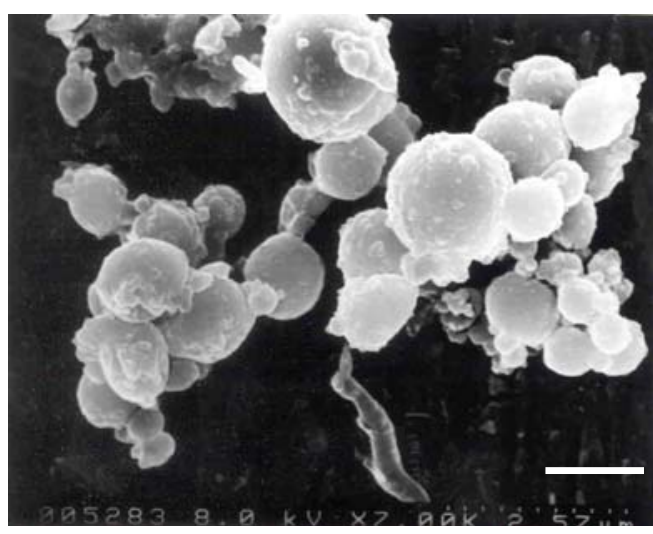

Fig. 3 PMMA synthesized with $0.5 \% \mathrm{v} / \mathrm{v}$ NFE and $10 \% \mathrm{v} / \mathrm{v}$ MMA Bar: $0.8 \mu \mathrm{m}$

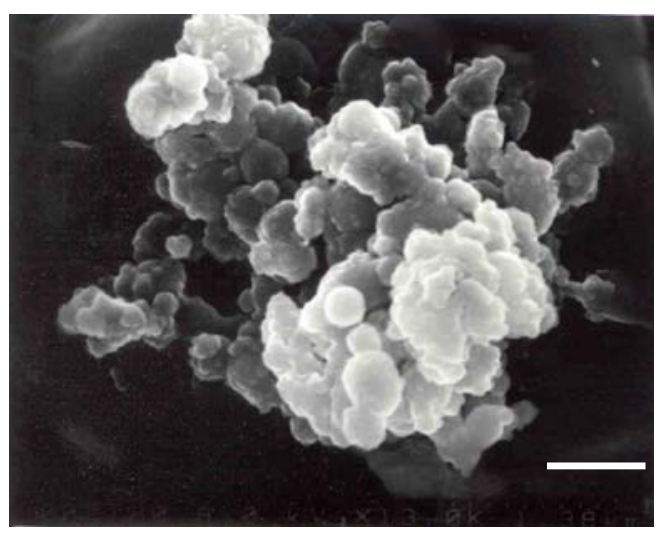

Fig. 2 PMMA synthesized with $2.0 \% \mathrm{p} / \mathrm{v}$ of CTAB and $10 \% \mathrm{v} / \mathrm{v}$ of MMA Bar: $0.4 \mu \mathrm{m}$

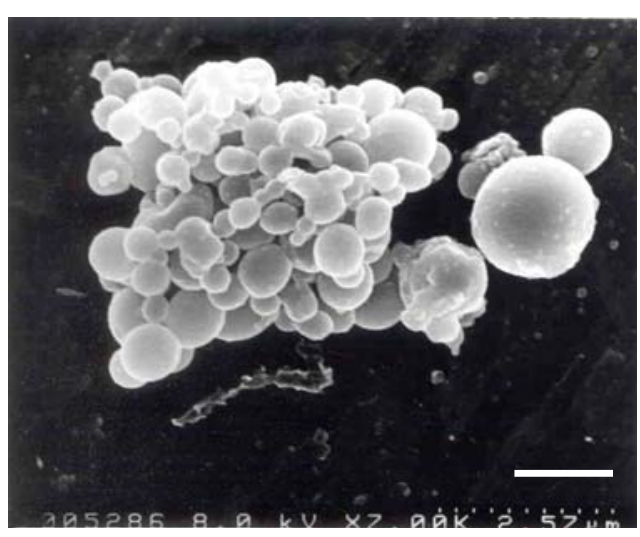

Fig. 4 PMMA synthesized with $2.0 \% \mathrm{v} / \mathrm{v}$ NFE and $10 \% \mathrm{v} / \mathrm{v}$ MMA Bar: $0.8 \mu \mathrm{m}$ 